\title{
ESTUDIO DE LAS POLÍTICAS DE INFORMACIÓN EN ARCHIVOS
}

\author{
Laura Cristina Torres Martínez*
}

\begin{abstract}
Resumen
El artículo se desarrolla en tres momentos; la primera parte corresponde a la delimitación conceptual de las políticas de información en archivos como un campo joven de los estudios de información. Así como sus antecedentes y tipificación. En la segunda parte se aborda el contexto y desarrollo de políticas por parte del Archivo General de la Nación, se explica cómo se fueron diseñando las políticas de información en los archivos, durante la segunda mitad del siglo xx y hasta llegar a la primera década del siglo XXI. Finalmente se hace una revisión de los planteamientos que las organizaciones internacionales globalizadoras hacen respecto de las políticas de información y de cómo estas impactan en las políticas de información en los archivos.
\end{abstract}

Palabras clave: políticas, información, archivos.

\begin{abstract}
The article is developed in three moments; the first part corresponds to de conceptual delimitation, background and typology of information policies in records/archives as a young field in the information studies. In the second part an approach of the context and development of policies by the Archivo General de la Nación is made, it explains how policies of information on records/archives were designed from the second half of the 20th century to the first decade of the 21st decade. Finally a review of the approaches made by the global organizations in relation with information policies and how these impact on information policies in records/archives is carried out.
\end{abstract}

Keywords: policies, information, records/archives.

*Profesora "Titular A", lautorres@sep.gob.mx; laura9119@yahoo.com 


\section{Antecedentes y concepto}

Las políticas de información como un campo joven de los estudios de la información, señalado a finales del siglo xx por Ian Rowlands, ${ }^{1}$ Mairéad Brown $^{2}$ y por Robert Burger ${ }^{3}$ manifiestan que es a través de los estudios de las políticas públicas como se puede comprender, estudiar y establecer su marco teórico; partiendo de lo anterior, se ha considerado que también pueden contribuir a la relación, orientación y acercamiento de las políticas de información en archivos.

Mairéad Browne apunta que las políticas de información tienen un origen histórico que ayuda a comprender cómo surgen y qué son. Establece como ejemplo, que desde el siglo XVI en Europa la Iglesia católica elaboró mecanismos para tener el control de la información, entre los poderes civiles, que pusieron restricciones a la ciencia, las artes, la política y la música. ${ }^{4}$

Durante los siglos XVII, XVIII y XIX se establecieron políticas de información a través del control de libros y archivos que eran censurados con uso restringido y a los cuales solo tenían acceso las clases altas, porque eran las que tenían poder sobre el pueblo, acceso al conocimiento y porque sabían leer, escribir y hablaban otros idiomas.

En el siglo xx se dio la apertura a las políticas de información que, a partir de los años sesenta, cobraron mayor importancia. Se estableció que la información es fundamental para la seguridad nacional y se dio peso especial a la propiedad intelectual. Un aspecto planteado fue la responsabilidad, en todos los países, del uso de la información.

Al término de la segunda guerra mundial, inició la llamada "guerra fría" - y la información tuvo un uso secreto, aspecto que los países cuidarían como parte de sus estrategias de poder-. Durante la "guerra fría", la sociedad demandaba información sobre la actuación de los gobiernos; esta solicitud llevó a Estados Unidos y a la entonces Unión Soviética a plantear la necesidad de normar el uso y la difusión de la información, sobre

1 Cfr. Rowlands, "Understanding information policy: concepts, frameworks and research tools", pp. 13-25.

2 Cfr. Brown, "The field of information policy, pp. 339-3351

3 Cfr. Burger, "The Analysis of Information Policy," pp. 171-181.

4 Browne, op. cit., p. 261. 
todo la militar y científica; debido a filtraciones en torno a los avances en materia espacial. Así surgió la instrumentación sobre el uso de las políticas de información.

Las políticas de información están relacionadas con la gobernabilidad a través de las instituciones; son promulgadas por cada gobierno, el cual decide lo que se debe hacer con la información y puede proyectarlas apoyándose en un plan de acción para el desarrollo y operación de servicios y sistemas de información. Abarcan la generación, organización, clasificación y recuperación de datos que son por sí mismos información, que una vez procesada se convertirá en conocimiento. La información puede considerarse como un bien al que la sociedad tiene derecho, es decir, es inalienable porque establece obligaciones, como la libertad de uso, y abre el camino a la sociedad democrática. Sin embargo, debe tener normas que protejan a la sociedad que las genera; por eso, las políticas sobre el uso de información restringen y protegen los documentos médicos, financieros, personales y el copyright, que pretende el uso justo del derecho al conocimiento. ${ }^{5}$

La frontera que delimita el acceso a la información depende de la importancia que cada sector o institución pública establece para dar a conocer asuntos sobre economía nacional, impuestos, moneda, educación, salud, energía, entre otras. Asimismo, algunos países consideran a las políticas de información como parte de las políticas de información gubernamentales. También son llamadas políticas expertas porque son promulgadas por un gobierno central que rige a sus secretarías de Estado y a los órganos de la administración pública.

En México, las secretarías de Estado, las organizaciones no gubernamentales y los entes públicos formulan políticas de información que someten a la aprobación de los poderes Ejecutivo y Legislativo. Estas instituciones se encargan del control, regulación y aplicación de las políticas para el beneficio de la sociedad. Horton apunta "que las políticas de información básicas deben estar encaminadas al proceso de producción, difusión y acceso a las mismas". ${ }^{6}$

5 Horton, "What are National Information Policies", pp. 3-12.

6 Ibid., p. 6. 
Por otra parte, una política de información debe estar sustentada en la generación de los datos; es decir, debe reflejar la metodología de uso y la credibilidad de los datos, así como la forma en que se recogieron y los propósitos que tenían; deberá además considerarse la propiedad legal, las leyes de propiedad intelectual, las innovaciones, la creatividad, la productividad, la propiedad de la información, la legislación secreta y la de dominio público, las cuales son aplicadas en los distintos sectores, según apunta Martha Dosa. ${ }^{7}$

Los gobiernos establecen políticas de información como guías para proteger, por un lado, los datos, y por otra parte, para usarlos y difundirlos. Estas pueden ser aplicadas de manera informal en la práctica del trabajo, o bien ser formales, plasmadas en leyes. Como un ejemplo del establecimiento de normas sobre el uso de la información, en 1991, el gobierno australiano señaló que los temas socioculturales, legales, el uso de datos, de información, conocimiento, economía, tecnología y política deben estar formulados bajo "políticas de información que atiendan su manejo, la acumulación, uso y difusión. Considerando que la información es la base de toda actividad social pública o privada"8 y que los componentes de una política de información deberían estar en estatutos legales, normas sociales, leyes públicas y acciones administrativas, como dice Trauth. ${ }^{9}$ Asimismo las políticas de información deben ser apoyadas por el gobierno.

\section{Políticas de información en archivos}

Cabe mencionar que en México son escasos los estudios sobre el tema. El estudio de las políticas de información tiene su origen en los acontecimientos históricos; su planteamiento no está alejado de lo acontecido en otros países, como se ha venido planteando.

Para el caso de los archivos, las políticas estuvieron presentes a lo largo de la historia y se dio atención a los documentos de archivo, cabe señalar que estos no fueron lo prioritario, porque había más atención en

7 Cfr. Dosa, Across all Borders: Internacional Information Flows and Applications: collected papers, pp. 239-251.

8 Horton., op. cit., p. 10.

9 Trauth, "An integrative approach to information policy research", pp. 41-50. 
las políticas económicas, en la política misma y, por supuesto, en lo social. En la Nueva España, había que depender de la corona española, lo cual limitaba en mucho la atención puntual de la documentación producida por la estructura colonial. De este periodo sobresale la ordenanza redactada por el segundo Conde de Revillagigedo, ${ }^{10}$ en la cual se establecía la creación del Archivo del Reino de la Nueva España, también llamado Archivo de la Secretaría del Virreinato; por lo que en un inicio las políticas de información se crearon según el concepto clásico de la archivística de conservar todos los documentos incorporando su arreglo, aunque no existían, en sentido estricto, métodos y técnicas de archivo.

Durante el siglo XIX la guerra de Independencia tuvo al país más ocupado en los asuntos latentes, que eran integrar un Estado-nación donde lo prioritario estaba inmerso en la conformación de una estructura política, el despegue económico y la atención de los problemas sociales; a pesar de esa situación, Lucas Alamán decretó el 22 de agosto de 1823 la creación de un Archivo Público General para el resguardo de todos los archivos diseminados y su base sería el antiguo archivo. Esto fue un logro político y también en las políticas de información, pues jurídicamente se instituyó el Archivo; en 1846 se publicó el decreto que reglamentó la organización del mismo; ${ }^{11}$ por ello, tomó relevancia que los documentos producidos por las administraciones fueran conservados y resguardados en los archivos como un bien de la nación.

Las políticas de información en archivos se establecieron, en una primera etapa, del siglo XVIII al XIX. Durante este periodo, la idea de sus creadores de preservar los documentos tuvo la finalidad de justificar y legitimar los derechos para sus sucesores. Posteriormente, en los albores del siglo xx, las políticas sobre los archivos señalaban la preservación y la conservación de los documentos. A estas se suma el control, desde su generación, para hacer más eficiente el uso y acceso a los documentos y a la información que contienen.

Las políticas de información conllevan decisiones que "pueden

10 Véase. Archivo General de la Nación de México, Fondo Reales Cédulas, vol. 151, fojas, 279-280.

11 Véase. Rubio Mané, Conmemoración del sesquicentenario de la fundación del Arcbivo General de la Nación, México, pp. 27-29 
[estar] encaminadas a obtener la mayor eficacia en la dirección, gestión y gobierno de las unidades de información, documentación [y archivo] en sentido amplio". ${ }^{12}$ A partir de lo anterior, la formulación de políticas de información en materia de archivos se basa en decisiones tomadas, por lo general, al más alto nivel de la administración pública. Las acciones planteadas deberán seguirse en todos los niveles inferiores. Las autoridades formulan planes sobre el control, manejo, organización, acceso y uso que seguirán los documentos en su ciclo vital, considerado como: "el progreso de cada documento a partir de sus tres fases que son la creación, uso y disposición final". ${ }^{13}$

Una política eficaz de archivos debe estar sustentada en dos elementos esenciales: "en la configuración de un sistema y en una planificación", afirma Esther Cruces Blanco. ${ }^{14}$ Así, la planeación se convierte en la espina dorsal de la política archivística y de su administración; pero no se debe confundir los términos, a veces considerados equivalentes, de programación y proyecto. La planificación es la elaboración de un plan general con ciertos objetivos. Cuando los objetivos son parciales, se habla de programas o proyectos". ${ }^{15}$ La planeación es una acción continua que programa acciones enfocadas a lograr ciertos objetivos, como puede ser la optimización de los recursos; se divide en varias etapas: diagnóstico de las necesidades, determinación de objetivos, soluciones, elaboración de directrices, decisiones, ejecuciones y evaluación.

Dentro de los elementos que se debe considerar para el establecimiento de las políticas de información en los archivos, Iraset Páez Urdaneta considera:

1. Se tiene que designar un comité nacional especial para determinar los alcances de la política. Las políticas de información plantearán objetivos de desarrollo en la dicotomía centralización/ descentralización operativa de la misma.

12 Ros García, Políticas de Información y Documentación, p. 13.

13 Tayfun, "A Model for Life Cycle Records Management”, pp. 1-15

14 Cruces Blanco, "El Futuro: la planificación archivística", citado por Ruiz Rodríguez, Manual de Archivística, p. 285.

15 Idem. 
2. Se determinarán funciones en la ejecución de las políticas, en los distintos organismos nacionales.

3. Se establecerán programas y presupuestos, a mediano plazo, que concuerden con los proyectos planteados en las instituciones públicas. ${ }^{16}$

Los recursos nacionales integrarán un sistema orientado a la información. Por tanto, la información que se guarda en los archivos sirve para la toma de decisiones en la administración pública y también es un recurso que tienen los individuos para la resolución de problemas de orden administrativo, como el conocimiento de su entorno social, del pasado, y de la cultura que lo forman.

Otra forma de determinar políticas de información se refiere al tratamiento de los documentos de archivo, estableciendo:

Medios que permitan el procesamiento eficaz y rentable de la documentación producida o acumulada por la administración. La finalidad de las políticas deberá ser la planificación, establecimiento y mantenimiento por medio de la reglamentación, estructura y programas racionales, eficaces y rentables sobre la creación, utilización, recuperación y conservación de los documentos que la administración produce o recibe durante el ejercicio de sus actividades. ${ }^{17}$

La política archivística implica desarrollar un plan que considere el tratamiento del documento de archivo y la información, además de las etapas activa o administrativa, la semiactiva o de concentración, donde se elimina o se selecciona y la inactiva donde se conserva en un archivo histórico.

16 Cfr. Páez Urdaneta, Información para el Progreso de América Latina, pp. 109-112.

17 Couture, Rousseau, Los Archivos en el Siglo XX, p. 15. 


\section{Clasificación de políticas de información en materia de archivos}

Richard Rubin ${ }^{18}$ hace mención de diferentes tipos de políticas de información en el ámbito bibliotecario, mismas que se puede considerar para los archivos:

- Política oficial. En las diversas formas de política archivística se debe considerar la oficial. Esta política emana del Estado y marca las formas de manejo y ordenamiento sobre los documentos de los archivos de la administración pública central. ${ }^{19}$ La política oficial se delega a la instancia correspondiente, en México el Archivo General de la Nación dicta, planea, ejerce y promueve las maneras de trabajo en los archivos.

- Política de organización documental. Es la instrumentación de la documentación que se implanta mediante un sistema nacional de administración documental. El sistema diseñará y aplicará, en forma gradual, una estrategia global para el manejo y uso de la documentación. La estrategia es una norma técnica coherente y completa de lineamientos y procesos para la gestión de todo el sector público, que incluye la producción, circulación, conservación, uso y selección de la documentación basada en el ciclo vital del documento.

18 Cfr. Rubin, Foundations of library and information science, pp. 139-169

19 Forest Woody Horton plantea algunos parámetros sobre política. El Estado tiene intenciones, comportamientos y normas que formaliza y hacen explícita la soberanía del gobierno. Sus instituciones, corporaciones y otras entidades organizacionales, como los grupos sociales, clubes y cuerpos profesionales.

Las políticas se desarrollan en forma individual, en las organizaciones e instituciones que se pueden considerar como micro-políticas. Se debe considerar que las políticas individuales no se establecen a partir de una ley. Existen otras políticas que se dan en toda la nación, región o a nivel internacional que se consideran macro-política.

Por otra parte, las políticas son necesarias en el sector público y privado. Las políticas son instrumentos formales y legales. Están plasmadas en Constituciones, actas parlamentarias, leyes, reglamentos, regulaciones, tratados internacionales y decisiones judiciales. Asimismo, se encuentran en manuales de procedimientos, guías de procedimientos, memorandos internos y documentos administrativos.

Las políticas sobre archivos incluyen el trabajo y ética de las personas que laboran en los repositorios y quedan plasmados en estatutos profesionales y códigos de ética, que trasmiten costumbres, creencias, tradiciones y valores sociales entre generaciones. Horton, "What are National Information Policies", pp. 3-5. 
- Política de desarrollo del acervo documental. Tiene como finalidad el crecimiento de los acervos históricos. Para recuperar la documentación, se debe considerar que contenga valores de evidencia, testimonio, información y de cultura, que son fuente y testimonio para la investigación y comprensión de la sociedad, así como para comprobar y legitimar las acciones de los ciudadanos. $\mathrm{Su}$ instrumentación estará sustentada en programas estratégicos de valoración, selección y catálogo de disposición documental. ${ }^{20}$ Los programas buscan asegurar la transferencia secundaria de documentos, ya sea para que queden resguardados en los archivos históricos o se haga la baja definitiva porque los documentos no llenan los parámetros para ser preservados y conservados.

- Política de preservación y conservación. Pretende optimizar y mejorar la guarda de los documentos por medio del control físico adecuado. También busca mejorar los edificios para mantener en buen estado la documentación.

- Política de conservación documental como patrimonio cultural. Surge por la preocupación del gobierno por conservar el patrimonio documental, y para conocer y preservar la identidad nacional. Los documentos son el reflejo de las actividades de la administración pública. En México, la preservación del patrimonio documental está sustentada en la "Ley Federal sobre monumentos y zonas arqueológicos, artísticos e históricos", " la cual establece en su artículo 36 fracción II que son monumentos históricos, los documentos y expedientes que hayan pertenecido o pertenezcan a oficinas y archivos de la federación, estados, municipios y casas curiales de los siglos XVI al XIX. El reglamento del Archivo General de la Nación ${ }^{22}$ establece, en los artículos 1 a 8, que los documentos de las oficinas

20 Instrumento elaborado a partir de la normatividad legal vigente con la finalidad de establecer tiempos de guarda y conservación de los documentos que deberán ser valorados para baja definitiva o de transferencia al archivo histórico. Se apoya en la ley sobre tiempos de guarda para documentación contable, y en los acuerdos emitidos para los tiempos de guarda de documentos judiciales.

21 "Ley federal sobre monumentos y zonas arqueológicos, artísticos e históricos", en Diario Oficial de la Federación, México, 6 de mayo de 1972.

22 Cfr. "Reglamento del Archivo General de la Nación", en Diario Oficial de la Federación, pp. 1 y 2. 
extinguidas que tengan interés histórico serán considerados como patrimonio nacional. Por otra parte, la protección del patrimonio documental se basa en la Ley General de Bienes Nacionales, ${ }^{23}$ que establece que son bienes de dominio público los objetos que por su naturaleza no son substituibles, como los documentos y expedientes de oficina, los archivos y las fotografías, entre otros.

- Política de Servicios Documentales. Busca mejorar los servicios de información documental determinada por la política de organización documental, que incluye el servicio de acceso y consulta. Los archivos ponen al acceso y la consulta de los documentos que resguardan a partir de diversos instrumentos que describen los documentos y que pueden ser: inventarios, listados, guías, catálogos en bases referenciales o de texto completo. También cabe mencionar que existen restricciones en el acceso a algunos documentos, por el tipo de información que contienen, y se les coloca en fondos y series documentales reservados, confidenciales o desclasificados. Asimismo, una forma de dar a conocer los acervos documentales son: las exposiciones, visitas guiadas y diversas publicaciones con documentación e información que se conserva en los archivos.

- Política sobre recursos humanos. Para aplicar políticas de desarrollo del acervo, preservación, conservación y servicio en los archivos, se debe incluir al personal que lleva a cabo los diversos procedimientos de trabajo en los archivos administrativos, de concentración e históricos. Los recursos humanos en los archivos tienen que operar en forma eficaz en cada etapa de ordenamiento documental. Para lograrlo, en los archivos se debe impulsar la formación de cuadros profesionales, así como cursos de capacitación para la administración de documentos.

\section{Actuación del Archivo General de la Nación: concepto y contexto de sus políticas}

El Archivo General de la Nación, durante la colonia, la independencia, y los

23 Cfr. "Ley General de Bienes Nacionales," en Diario Oficial de la Federación, pp. 14 y 15. 
siglos XIX y XX, se consolidó como la institución que resguarda y preserva documentos con información que refleja la historia de México.

Para comprender las políticas de información en los archivos es necesario analizar cómo en el Archivo General de la Nación, en distintas épocas, se conceptualizó al archivo, al documento y a la organización documental, así como la interacción entre documento e información. También se debe revisar la forma en que se conformó esta institución y cómo se ordenaron sus fondos documentales para que fueran utilizados por la administración pública, los ciudadanos y distintos profesionales en el ejercicio de su trabajo.

En este sentido solo abordaré lo acontecido en la segunda mitad del siglo xx sin menoscabo de los siglos anteriores. Considero que la época rompe en muchos sentidos la vieja situación decimonónica de darle un mayor trato a la preservación, custodia y resguardo.

En 1960, Ignacio Rubio Mañé fue designado director del Archivo General de la Nación. Entre las actividades que realizó se encuentran la innovación del boletín, promoviendo una segunda serie, con publicaciones históricas más profundas. Comenzaron las investigaciones históricas; y también se llevó a cabo la catalogación de varios fondos documentales con egresados del Colegio de Historia y de Archivonomía, de la Facultad de Filosofía y Letras de la UNAM.

Rubio Mañé inició relaciones con dos máximas autoridades internacionales en materia de archivos: el Consejo Internacional de Archivos y la unESCO, de la que fue vicepresidente de 1964 a 1968. También fue director y miembro honorario de la Sociedad Americana de Archivistas (The Society of American Archivist) y de los Archivos Nacionales (National Archives), de Washington, D.C. ${ }^{24}$ Durante su gestión se recibieron las donaciones de los siguientes documentos:

1. El Acta de la Independencia Nacional.

2. El Tratado de Ciudad Juárez del 21 de mayo de 1911, que dio fin a la dictadura de Porfirio Díaz.

24 Rubio Mañé, Conmemoración del sesquicentenario de la fundación del Archivo General de la Nación, México, , p. 65. 
3. Documentos, recortes de periódicos y fotografías del primer reparto de tierras hecho en México por el general Lucio Blanco, jefe de las fuerzas constitucionalistas, en Matamoros, Tamaulipas, en 1913.

4. Testamentos de los generales Antonio López de Santa Anna, de 1876, y Porfirio Díaz, de 1938.

5. Proceso contra José León Toral y socios, de 1928, que después fue retirado del AGN.

6. Proceso contra Felipe Carrillo Puerto, gobernador de Yucatán. ${ }^{25}$

En octubre de 1963, Luis Echeverría Álvarez, siendo secretario de Gobernación, se interesó por el archivo y los problemas que presentaba su sede. Para encontrar una solución al espacio, comisionó a Ignacio Rubio Mañé, para visitar los archivos de otros países y ver las condiciones de las instalaciones de los repositorios.

El Diario Oficial de la Federación publicó a finales de 1965 un decreto que determinaba la construcción de tres edificios donde se ubicarían la Secretaría de Gobernación, el Tribunal Federal de Conciliación y Arbitraje, y el AGN. Los edificios serían construidos entre las calles de Obrero Mundial, Doctor Vértiz, Esperanza y Petén. Estos inmuebles no se construyeron y se desconocen las causas de ello.

En 1969, un año antes de concluir la gestión presidencial de Díaz Ordaz, en la Dirección de Estudios Administrativos de la Presidencia, se realizaron reuniones para discutir la reforma administrativa. En el programa de Reforma para la Administración Pública Federal (1965-1979) se consideró a los archivos. Para conocer su situación se hicieron reuniones; se analizó la organización de los archivos públicos, los problemas de organización, formas de trabajo, recursos humanos y sedes. Alejandro Carrillo Castro, director de Estudios Administrativos, tuvo a su cargo los debates para hacer un diagnóstico que impulsó el trabajo archivístico; se formaron dos secciones: 1) archivos administrativos y 2) archivos históricos. Uno de los resultados fue el plan para crear una unidad administrativa de los archivos federales.

25 Idem. 
Los archivos en México trabajaban con criterios propios y dispersos, así que para que hubiera un trabajo coordinado e igual, la Comisión de Administración Pública y su Secretariado Técnico crearon el Comité Técnico Consultivo de las Unidades de Correspondencia y Archivo (Cotecuca, ${ }^{26}$ 1969), que ayudaría como mecanismo a: "coadyuvar al mejoramiento de los servicios de correspondencia y archivo de las entidades públicas, estudiar, analizar y proponer reformas en sistemas de organización y procedimientos para los archivos vinculados al Ejecutivo Federal". ${ }^{27}$ Así, el Archivo General de la Nación ${ }^{28}$ pudo normar políticas de los trabajos en los archivos en México y difundir los planteamientos formulados por el Cotecuca y los Comités Técnicos Internos de Administración de Documentos (Coteciad). ${ }^{29}$

En tanto en su sede el Archivo recibió la documentación de los XIX Juegos Olímpicos, el 26 de noviembre de 1970. De igual manera, se continuó con la catalogación de los fondos de la época colonial y se publicaron los dos primeros tomos del Índice del Fondo Provincias Internas y del Índice del Fondo de Reales Cédulas.

Rubio Mañé, al finalizar su administración, dijo:

En la vida del AGN, tres [eran] sus grandes menoscabos 1) carencia de un edificio propio, adecuado y funcional; 2) administración eficaz del Estado, que atienda oportunamente sus requisitos; y 3) personal calificado, con estudios competentes en Archivonomía e Historia bien remunerados con salarios dignos, de modo que sus funciones iluminen el camino a los que investigan, y sus actividades proporcionen bases a la averiguación histórica de nivel científico. ${ }^{30}$

A continuación se presenta un cuadro en el que se despliega el tipo de políticas de información que el AGN fue implementando.

26 Comité Técnico Consultivo de las Unidades de Correspondencia y Archivo, de aquí en adelante Cotecuca.

27 Villaneda, Historia del Comité Técnico Consultivo de las Unidades de Correspondencia y Archivo, p. 12.

28 De aquí en adelante AGN.

29 Comités Técnicos Internos de Administración de Documentos, de aquí en adelante Coteciad.

30 Rubio Mañé, op. cit., p. 69. 


\section{Cuadro 1. Situación del archivo y aCciones EN LA ÉPoca POSREVOLUCIONARIA (1920-1977)}

\begin{tabular}{|c|c|c|c|}
\hline Contexto (Actores) & Archivo & Tipo de políticas & Acciones \\
\hline $\begin{array}{l}\text { Presidente Lázaro } \\
\text { Cárdenas del Río } \\
\text { Director Rafael } \\
\text { López,1920-1943 }\end{array}$ & $\begin{array}{l}\text { Archivo } \\
\text { General } \\
\text { de la Nación }\end{array}$ & $\begin{array}{l}\text { Organización } \\
\text { documental } \\
\text { Servicios } \\
\text { documentales }\end{array}$ & $\begin{array}{l}\text { Creación de un } \\
\text { departamento para } \\
\text { clasificar la documentación } \\
\text { de la Secretaría de } \\
\text { Hacienda. } \\
\text { Publicación del Boletín del } \\
\text { AGN }\end{array}$ \\
\hline $\begin{array}{l}\text { Presidente Manuel } \\
\text { Ávila Camacho, } \\
\text { 1940-1946 } \\
\text { Director Julio } \\
\text { Jiménez Rueda, } \\
\text { 1943-1952 }\end{array}$ & $\begin{array}{l}\text { Archivo } \\
\text { General de la } \\
\text { Nación }\end{array}$ & $\begin{array}{l}\text { Preservación y } \\
\text { conservación } \\
\text { Servicios } \\
\text { documentales } \\
\text { Organización } \\
\text { documental }\end{array}$ & $\begin{array}{l}\text { Propuesta para instalar el } \\
\text { AGN en los edificios de La } \\
\text { Ciudadela. } \\
\text { Apoyo de la UNAM para } \\
\text { iniciar la nueva serie del } \\
\text { Boletín. Cooperación } \\
\text { del Instituto Indigenista } \\
\text { para publicar el índice } \\
\text { del fondo Indios. La SHCP } \\
\text { destinó una partida para la } \\
\text { catalogación de los fondos } \\
\text { de Inquisición, Criminal, } \\
\text { Universidad y Provincias } \\
\text { Internas. Instalación de } \\
\text { equipos de desinfección. } \\
\text { Se hizo copia de tarjetas } \\
\text { catalográficas. Adquisición } \\
\text { de equipo de micropelícula }\end{array}$ \\
\hline & & Recursos Humanos & Aumentó el personal \\
\hline $\begin{array}{l}\text { Presidentes: } \\
\text { Adolfo Ruiz } \\
\text { Cortines, } \\
\text { 1952-1958 } \\
\text { Gustavo Díaz } \\
\text { Ordaz, 1964-1970 } \\
\text { Directores: } \\
\text { Manuel B. Trens, } \\
\text { 1953-1959 } \\
\text { Ignacio Rubio } \\
\text { Mañé, 1960-1977 }\end{array}$ & $\begin{array}{l}\text { Archivo } \\
\text { General de la } \\
\text { Nación }\end{array}$ & $\begin{array}{l}\text { Servicios } \\
\text { documentales }\end{array}$ & $\begin{array}{l}\text { Se recibieron donaciones } \\
\text { de documentos, como el } \\
\text { Acta de Independencia } \\
\text { Nacional y } 95 \text { documentos } \\
\text { de Benito Juárez. } \\
\text { Se intensificaron las } \\
\text { relaciones con el Consejo } \\
\text { Internacional de Archivos. }\end{array}$ \\
\hline
\end{tabular}




\begin{tabular}{|c|c|c|c|}
\hline Contexto (Actores) & Archivo & Tipo de políticas & Acciones \\
\hline $\begin{array}{l}\text { Presidentes: Luis } \\
\text { Echeverría } \\
\text { 1970-1976 }\end{array}$ & Archivo & Oficial & $\begin{array}{l}\text { Reforma del Estado. Se } \\
\text { analizan los problemas } \\
\text { de los archivos públicos y } \\
\text { se presenta un plan para } \\
\text { mejorar su administración. }\end{array}$ \\
\hline \multirow[t]{2}{*}{$\begin{array}{l}\text { Director Ignacio } \\
\text { Rubio Mañé, } \\
\text { 1960-1977 }\end{array}$} & $\begin{array}{l}\text { General de la } \\
\text { Nación }\end{array}$ & $\begin{array}{l}\text { Preservación } \\
\text { documental }\end{array}$ & $\begin{array}{l}\text { En } 1970 \text { se traslada la } \\
\text { documentación de los XIX } \\
\text { Juegos Olímpicos. }\end{array}$ \\
\hline & & $\begin{array}{l}\text { Organización } \\
\text { documental }\end{array}$ & $\begin{array}{l}\text { Aumentó la catalogación } \\
\text { de fondos }\end{array}$ \\
\hline
\end{tabular}

\section{Época contemporánea (1977-2000)}

José López Portillo decretó el 27 de marzo de 1977 que el Palacio de Lecumberri albergaría el Archivo General de la Nación, siendo sus sedes anteriores el Palacio Nacional y el Palacio de Comunicaciones hasta 1982. Alejandra Moreno Toscano, como directora del AGN, entre 1977 y 1982, realizó un intenso trabajo para reformar y modernizar al Archivo. Durante esta administración fue receptor de los documentos generados por las dependencias y órganos de la administración pública. Moreno Toscano planteó nuevas formas de abatir la producción de documentos en las entidades de la administración pública. Entre los factores que propiciaron replantear el tratamiento de los documentos de archivo estaban: el crecimiento de la Administración Pública Federal y por ende la mayor producción de documentos en las oficinas, el abandono que se tenía de los mismos, la falta de metodologías para su tratamiento, los pocos profesionales que atendieran las necesidades y sobre todo que el Estado no tenía directrices que orientaran el rumbo de los archivos y de la información. ${ }^{31}$

Para resolver los problemas y para que el Archivo General de la Nación tuviera un papel eficaz, José López Portillo, dispuso el 14 de julio de 1980 por decreto presidencial, que el AGN "será la entidad central y de consulta

31 Cfr. México, Dirección General de Estudios Administrativos. Las Unidades de Correspondencia y archivo en el sector público federal: Guía para su organización y funcionamiento, pp. 1-29 
del Ejecutivo Federal en el manejo de los archivos administrativos e históricos de la Administración Pública Federal". ${ }^{32}$ Esta institución, al ser designada la entidad central para el manejo de archivos, tuvo que establecer una reestructuración. Uno de los cambios internos fue la creación de la Coordinación de Archivos Administrativos.

Bajo la dirección de Leonor Ortiz Monasterio, de 1983 a 1994, el AGN enfrentó la reforma y modernización de los archivos. Se renovó la forma de concebir a los archivos de la administración pública. Un punto a destacar es que el AGN tuvo una relación más estrecha con organismos internacionales de archivos, lo cual permitió adquirir diversas experiencias que lo enriquecieron. Participó en los Congresos del Consejo Internacional de Archivos (ICA). Estableció convenios en Latinoamérica con Argentina y Brasil. Asimismo concertó alianzas con Estados Unidos, Canadá, España, Italia, Francia e Inglaterra, para compartir los avances de organización y trabajo en sus archivos.

El AGN replanteó sus funciones y estructura para cumplir con su deber, constituyó la Coordinación de Archivos del Gobierno Federal; y posteriormente conformó el Sistema Nacional de Archivos, ejes fundamentales de coordinación para las actividades archivísticas. Para coordinar las actividades de los archivos en el país, el AGN impulsó programas sobre Administración de Documentos, que abarcaron subprogramas de normatividad técnica y jurídica. Se desarrollaron y se ofrecieron cursos de capacitación para los archivos del gobierno federal y para organismos descentralizados, de participación estatal y de los gobiernos estatales y municipales.

También amplió el programa editorial, con publicaciones sobre métodos y técnicas de ordenación, clasificación y conservación de archivos. Los nuevos enfoques que planteó el AGN en las publicaciones hicieron explícitos los cambios en la concepción de la administración de archivos, a diferencia del antiguo Boletín del Archivo General de la Nación, que estaba dedicado a la difusión de las fuentes documentales del archivo y a la explotación de las fuentes utilizadas por los investigadores que acudían al archivo; cabe

32 "Acuerdo por el que se dispone que el AGN será la entidad central y de consulta del Ejecutivo Federal en el manejo de los archivos administrativos e históricos de la Administración Pública Federal", en Diario Oficial de la Federación, pp. 4-5. 
destacar que los Manuales del Sistema Red de Arcbivos, ${ }^{33}$ fueron publicaciones que sirvieron de orientación en las tareas archivísticas de los archivos de la administración pública federal y que tuvieron cobertura a nivel nacional.

Ortiz Monasterio organizó reuniones anuales de archivistas, que congregaban a un gran número de participantes y como parte de su nuevo papel, el AGN realizó diferentes exposiciones, entre las que se destacó Caminos de la Libertad. La Independencia de México 1801-1821, en 1985, con motivo del 75 aniversario del movimiento de Independencia en nuestro país. Otra fue la publicación de la Guía General, que contiene la descripción del progreso de las diferentes fases de organización de los 322 grupos documentales resguardados hasta ese momento. ${ }^{34}$ Este trabajo fue la raíz para construir, tiempo después, una base de datos referencial denominada Argena, que contenía la mayoría de grupos de la época colonial.

Hacia finales del siglo xx, entre 1994 y 1999, Patricia Galeana tomó la dirección del AGN; esta administración atravesó por una crisis política y económica severa. Durante este periodo hubo falta de presupuesto; se promovió que el personal tomara retiros voluntarios y hubo escasez de material para realizar los trabajos diarios.

En materia de publicaciones, se retomó la publicación del Boletín del Archivo General de la Nación, con temas enfocados al uso de fuentes documentales en estudios históricos, sociológicos, antropológicos, literarios, jurídicos, económicos y arquitectónicos; es decir, en investigaciones de ciencias sociales. Durante esta administración, se realizaron eventos sobre archivos e investigaciones en ciencias sociales con los documentos que se guardan en los archivos históricos de la administración pública, para que se conociera el papel de los repositorios en la sociedad. También continuaron las relaciones con archivos e instituciones de archivonomía nacionales e internacionales. El Archivo impartió cursos de capacitación al personal de esta institución y de otros archivos por medio de diplomados para capacitar a los archivistas. ${ }^{35}$

33 Los manuales han servido de orientación en la organización de los archivos públicos, mismos que retoman la visión del ciclo vital del documento a partir de la administración documental, acuñada por la corriente anglosajona, a través de las obras de Theodore $\mathrm{T}$. Schellenberg, Carol Couture y Jean-Yves Rousseau.

34 Cfr. Herrera Huerta, San Vicente Tello (coords.), Guia General, 1990. 


\section{Cuadro 2. Situación del archivo y aCciones EN la ÉPoca CONTEMPORÁNEA (1977-1999)}

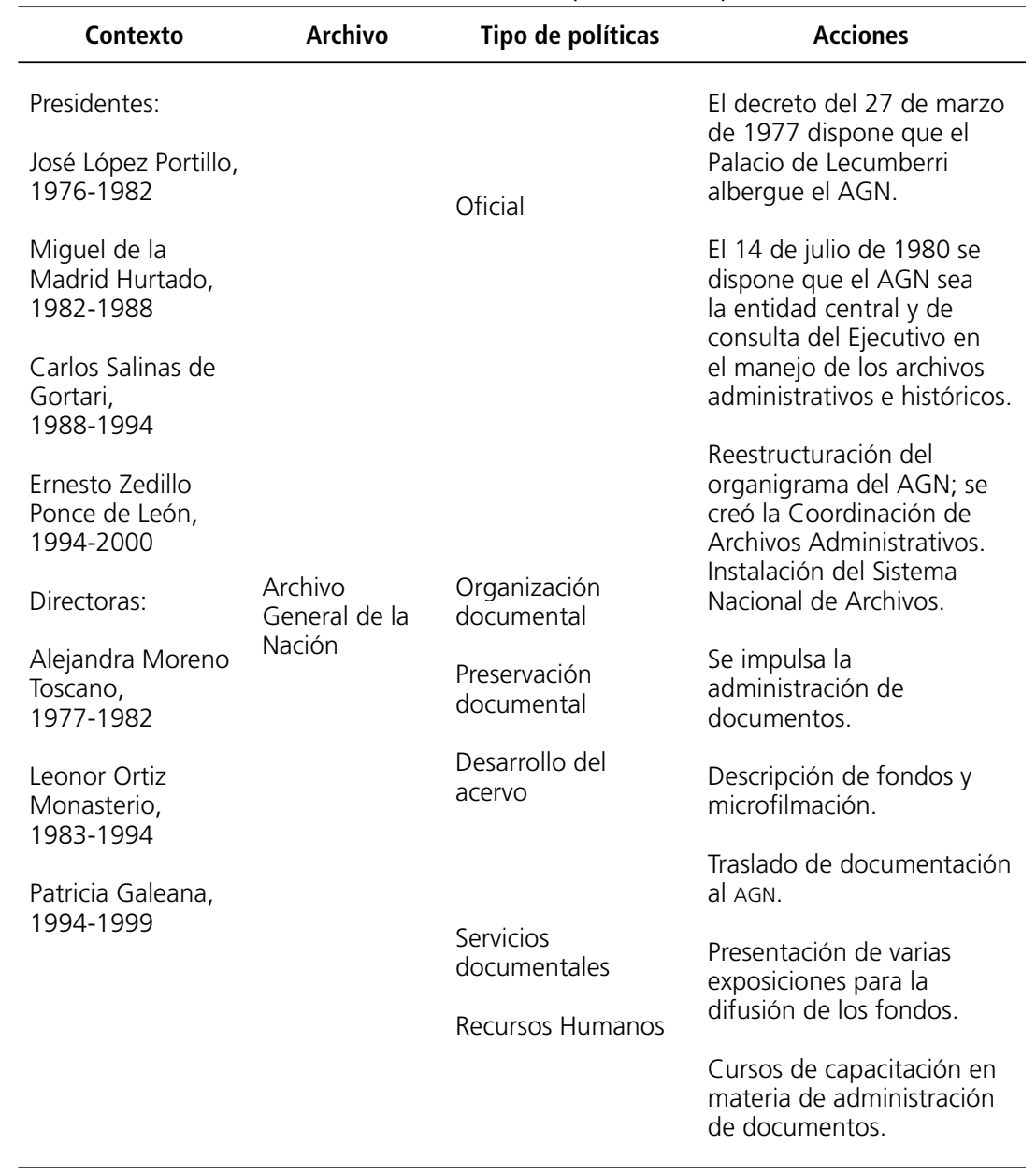

35 Véase Secretaría de Gobernación, Informes de Labores de la Secretaría de Gobernación, 1994-1999. 


\section{Políticas de información en la primera década del siglo XxI}

A finales del siglo xx el entorno internacional marcó una serie de acontecimientos que las sociedades paulatinamente fueron asimilando, por una parte las políticas ante el fenómeno globalizador que en un inicio giró en torno a los aspectos económicos, pero que al paso del tiempo trastocó lo ambiental y lo social. La globalización para Arturo Ramos Pérez y siguiendo a Held.

Se presenta como un nuevo orden internacional que envuelve la emergencia de un sistema económico global que se estira más allá del control de un estado singular (incluso de los estados dominantes); la expansión de las redes de nexos y comunicaciones, transnacionales sobre las cuales los estados particulares tienen poca influencia; el crecimiento enorme en la organización internacional que puede limitar el alcance de la acción de los más poderosos estados; el desarrollo de un orden militar [...] el cual puede reducir el rango de viabilidad de las políticas de los gobiernos y sus ciudadanos. ${ }^{36}$

Por otra parte el neoliberalismo como eje de la reestructuración del capitalismo mundial y del Estado, tuvo como consecuencia las denominadas autopistas de la información y de:

Acciones que fueron concertadas a través de instancias estratégicas y ejecutivas como el grupo de las siete potencias conocido como G- $7^{37}$ y que más tarde en 1999 se convertiría en el G-20 al cual pertenecen países altamente industrializados y países que recientemente se consideran industrializados, entre las formas de operar es mediante el Fondo Monetario Internacional, (FMI), el Banco Mundial (BM), la Organización para la Cooperación y el Desarrollo Económico (OCDE) y en algunas ocasiones la Organización de las Naciones Unidas". ${ }^{38}$

36 Ramos Pérez, Globalización y neoliberalismo: ejes de la restructuración del capitalismo mundial y del estado en el fin del siglo XX, p. 21.

37 Conformado por los países más industrializados: Estados Unidos, Alemania, Reino Unido, Italia, Canadá, Francia y Japón.

38 Ramos Pérez, op. cit, p. 103. 
En este sentido el Banco Mundial estableció que el Estado debería cumplir siete funciones fundamentales: 1) garantizar la estabilidad macroeconómica y el ambiente propicio para la competencia capitalista, 2) mantener el orden público, 3) invertir en el capital humano, 4) construir una infraestructura productiva, 5) proteger el medio ambiente, 6) controlar la natalidad, 7) la importancia de la gestión pública para la eficacia y la eficiencia. Enfatizando, pues, la noción de gobernanza definida como la forma mediante la cual el poder es ejercido administrando los recursos sociales y económicos de un país para el desarrollo; el camino sería el estímulo a la participación comunitaria en la gestión de las políticas públicas. Esto favorecería la asignación y uso eficiente de los recursos públicos, la transparencia de la administración y la responsabilidad y la rendición de cuentas de la burocracia sobre sus actividades. $^{39}$

Otro de los organismos que marca las pautas mundiales en materia económica es la Organización para la Cooperación y Desarrollo Económico conocida como (OCDE) del cual México es miembro desde 1994. Este organismo tiene como principios el:

Respeto al tema de gobernabilidad, [porque] promueve el buen gobierno en todos los niveles gubernamentales y empresariales; fomenta la transparencia y la equidad de la regulación en los sistemas impositivos y las reglas de competencia; lucha contra la corrupción y el lavado de dinero, promueve la conducta ética; e impulsa el principio de rentabilidad de los poderes públicos y la participación de los ciudadanos en la toma de decisiones. ${ }^{40}$

El Fondo Monetario Internacional (FMI) por su parte presta una alta atención a la buena gestión de los gobiernos que son miembros; abarca todos los aspectos relacionados con la forma en que un país es gobernado. Su marco regulatorio, así como su adhesión al Estado de derecho, la corrupción, el

39 Mendes Pereira, "El banco mundial y la reforma del estado: ¿más allá del consenso de Washington?, p. 5, 6 [En línea] http://www.pvp.org.uy/mendesspereira.htm [consultado 18 de octubre de 2012]

40 Véase "México y los esfuerzos anticorrupción de la OCDE: Acerca de la OCDE". [en línea] http://www.funcionpublica.gob.mx/ocde/acerca/info.html [consultado $17 \mathrm{de}$ octubre de 2012] 
abuso de la autoridad o la confianza pública en beneficio privado es un concepto estrechamente vinculado: un entorno en el que la gestión de gobierno es deficiente ofrece mayores incentivos y oportunidades para que exista corrupción, en 1997 el FMI adoptó una política sobre cómo abordar la gestión de gobierno en el ámbito económico, que está consignada en la nota de orientación titulada El papel del FMI en materia de gestión de gobierno.

[...] las condiciones estructurales de los programas respaldados por el FMI se centraron en [...] un mejor control del gasto fiscal, la publicación de las cuentas auditadas del gobierno y entidades estatales, una administración de ingresos simplificada y menos discrecional, una mayor transparencia en la gestión de los recursos naturales, la publicación de las cuentas auditadas del banco central y una aplicación más estricta de la supervisión bancaria.

$[\ldots]$

El FMI procura que los países miembros mejoren la rendición de cuentas reforzando la transparencia en la divulgación de documentos, de acuerdo con lo contemplado en su política de transparencia.

Junto con el Banco Mundial, el FMI evalúa el cumplimiento de los países miembros con las normas internacionales sobre transparencia en 12 ámbitos de política como parte de la Iniciativa sobre Normas y Códigos, que abarca el gobierno, el sector financiero y el sector empresarial.

$[\ldots]$

Para lograr una mayor transparencia, calidad y puntualidad de los datos, el FMI insta a sus miembros a suscribirse a las Normas Especiales para la Divulgación de Datos (NEDD) o a que participen en el Sistema General de Divulgación de Datos (SGDD) [...]. ${ }^{41}$

Así, una vez marcadas las políticas por estos organismos a nivel mundial en el contexto nacional, se fueron construyendo políticas acordes para mejorar la situación del fin del siglo xx, pues prevalecían instituciones de gobierno

41 "El FMI y la buena gestión de gobierno", [en línea] http://www.imf.org/external/np/exr/ facts/spa/pdf/govs.pdf, [consultado 23 de octubre de 2012] 
poco confiables para la entrada de capitales e inversiones internacionales y nacionales, y en específico no era posible el gran proyecto neoliberal sobre el Tratado de libre comercio con Estados Unidos y Canadá (TLCAN) el cual se firmó en 1992 y entró en vigor en 1994.

Así para que las economías de transnacionales apostaran en la inversión de un país como México la condición era contar con un país organizado políticamente donde la democracia jugara un papel fundamental para que la ciudadanía creyera en sus gobernantes.

Lo anterior no bastaría ante el contexto mundial, pues se requería que las organizaciones internacionales confiaran en la gobernanza de los Estados miembros y de que el ciudadano participara en la toma de decisiones en sus instituciones.

Si bien la Constitución Política de los Estados Unidos Mexicanos en su artículo $6^{\circ}$ hace referencia a que la información será garantizada por el Estado, desde la década de los 70, es hasta 2007 cuando se le agregan a este artículo los apartados de la información confidencial y reservada.

La política del gobierno a finales del siglo xx mencionaba que la información económica y social podría ser consultada a través del INEGI. Además de que se continuaría con el compromiso de "preservar y custodiar los acervos y los archivos de la nación y se perfeccionaran las modalidades de entrega oportuna de información y documentación oficial para su resguardo y consulta pública". ${ }^{42}$ En esta línea los archivos de la administración pública seguían, en la práctica y en la política, como los custodios de la información que generaban, y mínimamente la información fluía.

A inicios del siglo XXI se dio un giro en lo político y en la forma de concebir al Estado, la nación y la idea de democracia, haciendo énfasis en que los gobernados deben tener derecho a una mayor participación ciudadana, a elegir a sus gobernantes y conocer en qué se invierten las finanzas públicas; ante tal situación el gobierno delimitó en el Plan Nacional de Desarrollo 2001-2006 un apartado sobre gobernabilidad democrática en donde se comprometía a que:

42 Poder Ejecutivo Federal. Plan Nacional de Desarrollo 1995-2000, p. 69. 
Las dependencias de la administración pública federal colaborarán para que la ciudadanía esté mejor informada [...] así mismo facilitaran el acceso a la información de fuentes oficiales conforme al marco normativo. En el apartado de Transparencia el Ejecutivo Federal actuará con transparencia en el ejercicio de sus facultades, por lo que los servidores públicos de la administración pública federal estarán obligados a informar con amplitud y puntualidad sobre los programas que tienen encomendados, en términos de logros alcanzados y recursos utilizados. ${ }^{43}$

Lo que en palabras de Horton se tipifica como una política experta o macro política, derivado de este contexto en 2002 se publicó la Ley federal de transparencia y acceso a la información pública gubernamental (LFTAIPG). ${ }^{44}$ Para cumplir con esta idea de la transparencia, en el pasado solo se consideraba la importancia de los archivos históricos porque estos proporcionaban información a ciertos sectores de la sociedad. Entrado el siglo XXI los archivos de gestión juegan un papel importante pues generan datos e información valiosa para la ciudadanía y sus gobernantes, y porque estos deben cumplir con el objetivo del ideal de una sociedad democrática.

En este sentido se produjo una nueva forma de ver a los archivos institucionales, ya que estos producen y generan información de las actividades y funciones producto de la administración pública gubernamental, misma que utilizan desde los niveles más altos hasta los ciudadanos. Por ello, para alcanzar el escenario expuesto por los organismos internacionales y las políticas neoliberales, la LFTAIPG estableció los mecanismos para que la información producida por los entes públicos pudiera ser consultada, más adelante se insistió y se manifestó en diferentes foros que su aplicación no era posible por de la falta de atención y del poco seguimiento de políticas de información en la organización documental de los archivos públicos, ${ }^{45}$ de ahí que la ley reconocía la cooperación de otras instancias y de otras instituciones para llevar a cabo el cometido. El papel rector del Archivo

43 Poder Ejecutivo Federal. Plan Nacional de Desarrollo 2001-2006, pp. 44-45

44 Véase. "Ley Federal de Transparencia y Acceso a la Información Pública Gubernamental", Diario Oficial de la Federación, 8-junio-2012, pp. 1-25. De aquí en adelante LFTAIPG.

45 Véase. Foro global sobre transparencia e intercambio de información para fines tributarios. [en línea] http://www.ciat.org/index.php/novedades/historico-de-noticias/noticia/2420foro-global-sobre-transparencia-e-intercambio-de-informacion-para-fines-tributarios.html 
General de la Nación ha sido importante en materia archivística, lo cual sin duda se ha manifestado en su labor a lo largo de más de tres siglos.

Otra instancia involucrada en ejercer la política de la transparencia y del acceso a la información fue creada por la misma Ley: el Instituto Federal de Acceso a la Información (IFAI), el cual establece los mecanismos de acción para que la información de los entes obligados esté al servicio de sus gobernados.

En esencia podemos decir que la LFTAIPG es una política de información, porque señala quiénes deben acatarla, para qué se dicta, quién está obligado a proporcionar la información pública, qué mecanismos se deberán implementar para que esto se cumpla y las acciones que se deberán seguir.

En este sentido la LFTAIPG involucra y convierte la actuación del AGN en el diseñador de los mecanismos e instrumentos normativos para cumplir el cometido de dicha ley, se pueden encontrar antes de publicada la Ley Federal de Archivos, los siguientes instrumentos:

Lineamientos para la organización y conservación de los archivos de las dependencias y entidades de la administración pública federal.

Instructivo para baja documental de los archivos del Gobierno Federal.

Guía para la identificación de series documentales con valor secundario 2009.

Instructivo para elaborar el Cuadro general de clasificación archivística 2012.

Instructivo para elaborar el Catálogo de disposición documental 2012.

Instructivo para la transferencia secundaria de archivos en (soporte papel) dictaminados con valor histórico por el Archivo General de la Nación 2010.

Instructivo para la elaboración de la Guía simple de archivos.

Finalmente es de suma importancia mencionar otro gran logro, me refiero a la aprobación de la Ley Federal de Archivos, ${ }^{46}$ misma que viene a contribuir en la atención de las distintas políticas de información en archivos y de otras que es necesario ir planteando; sería inapropiado en esta exposición especular de manera premeditada sobre lo que pasará en los próximos años,

46 Véase "Ley Federal de Archivos", Diario Oficial de la Federación, 23 de enero de 2012. 
solo destacaré que en ella se encuentran políticas de información marcadas para los archivos públicos, privados, y que debe considerarse la nueva tendencia de los archivos que se encuentran en ambiente digital; por otra parte, la ley retoma mucho de las diferentes propuestas elaboradas, como la estructura para operar y su implantación en el corto plazo.

\section{Conclusiones}

Las políticas de información en archivos tienen un papel trascendente, pues han contribuido a la conservación de la memoria de las instituciones, sobre todo porque en los archivos se resguardan no solo los documentos que dan cabida al actuar de los organismos públicos en el devenir histórico, sino porque también se encuentra información que le permitirá a las instituciones, por una parte, tomar las mejores decisiones, y por otra parte, si la información es considerada como un recurso en la vida social, política y económica, entonces debe ser de libre acceso, tanto y entonces para los ciudadanos, como para las instituciones, empresas, sindicatos, asociaciones, etcétera.

Las políticas de información son muy necesarias porque marcan los lineamientos para su uso, acceso, transparencia y rendición de cuentas, mismas que se conjugan para que se cumpla el ideal de la democracia de un país.

\section{Bibliografía}

"Acuerdo por el que se dispone que el AGN será la entidad central y de consulta del Ejecutivo Federal en el manejo de los archivos administrativos e históricos de la Administración Pública Federal," en Diario Oficial de la Federación, México, 14 de julio de 1980, pp. 4-5.

Browne, Mairéad, "The field of information policy: 1. Fundamental concepts," en Journal of Information. Science, vol. 23, núm. 4, 1997, 261-275.

Burger, Robert. "The Analysis of Information Policy," en Library Trends, Summer, 1986, pp.171-181.

Couture Carol, Jean-Yves Rousseau. Los Archivos en el Siglo XX, Nora Settels Sandahl (trad.), México, Archivo General de la Nación, 1988. 
Cruces Blanco, Esther, "El Futuro: la planificación archivística", en II Congreso de Arcbivos de Castilla y León, Palencia, 1994. Citado en Ruiz Rodríguez, Antonio Ángel. Manual de Archivística. Madrid, Síntesis, 1995, p. 285.

Dosa, Marta, Across all Borders: Internacional Information Flows and Applications:collected papers, Lanham, Maryland., Scarecrow Press, 1997.

"El FMI y la buena gestión de gobierno", [en línea] http://www.imf.org/ external/np/exr/facts/spa/pdf/govs.pdf, [consultado 23 de octubre de 2012]

Herrera Huerta, Juan M. y Victoria San Vicente Tello (coord.), Guia General, México, Secretaría de Gobernación, Archivo General de la Nación, 1990.

Horton Jr., Forest Woody. "What are National Information Policies", en International Forum on Information and Documentation, vol. 23, núm. 1 january-march, 1998, p. 3-5.

"Ley General de Bienes Nacionales", Diario Oficial de la Federación, México, 8 de enero de 1982, pp. 14 y 15.

"Ley Federal de Monumentos y Zonas Arqueológicas, Artísticos e Históricos", en Diario Oficial de la Federación, México, 6 de mayo de 1972.

"Ley Federal de Transparencia y Acceso a la Información Pública Gubernamental", en Diario Oficial de la Federación, (última reforma) 8 de junio de 2012, pp. 1-25.

"Ley Federal de Archivos", en Diario Oficial de la Federación, 23 de enero de 2012.

Mendes Pereira, Joao Márcio. "El banco mundial y la reforma del estado": ¿más allá del consenso de Washington? [En línea] http://www.pvp.org. uy/mendesspereira.htm [consultado 18 de octubre de 2012].

"México y los esfuerzos anticorrupción de la OCDE: Acerca de la OCDE", [en línea] http://www.funcionpublica.gob.mx/ocde/acerca/info.html [consultado 17 de octubre de 2012].

Páez Urdaneta, Iraset, Información para el Progreso de América Latina, Caracas, Universidad Simón Bolívar, 1990.

Poder Ejecutivo Federal, Plan Nacional de Desarrollo 1995-2000, México, Poder Ejecutivo Federal, 2005.

Poder Ejecutivo Federal, Plan Nacional de Desarrollo 2001-2006, México, 
Poder Ejecutivo Federal, 2001.

Ros García, Juan, José López Yepes, Políticas de Información y Documentación, Madrid, Síntesis, 1994.

Ramos Pérez, Arturo, Globalización y neoliberalismo: ejes de la restructuración del capitalismo mundial y del estado en el fin del siglo XX, México, Plaza y Valdés, 2002.

"Reglamento del Archivo General de la Nación", en Diario Oficial de la Federación, México, 3 de diciembre de 1946.

Rowlands, Ian. "Understanding information policy: concepts, frameworks and research tools", Journal of Information Science, núm. 22 (1), 1996, pp. 13-25.

Rubio Mañé, Ignacio, Conmemoración del sesquicentenario de la fundación del Arcbivo General de la Nación México 1823-1973, México, Secretaría de Gobernación, AGN 1973.

Secretaría de Gobernación, Informes de Labores de la Secretaría de Gobernación, 1994-1999.

Tayfun, Angela C., "A Model for Life Cycle Records Management”, CRM, Records Manager, TRW Environmental Safety Systems, Sherrill Gibson, $\mathrm{s} / \mathrm{f}$.

Trauth, E. M. "An integrative approach to information policy research", en Telecomunication Policy, núm. 10 (1), 1986, pp. 41-50.

Villaneda, Alicia, Historia del Comité Técnico Consultivo de las Unidades de Correspondencia y Archivo, México, Secretaría de Gobernación, Archivo General de la Nación, 2004. 